\title{
Metachronous bladder metastasis from papillary renal cell carcinoma
}

\author{
Arun Ramdas Menon', Nivedita Suresh², Prajwal Ravinder ${ }^{1}$, Rajeev Thekke Puthalath ${ }^{1}$ \\ ${ }^{1}$ Department of Urology, K S Hegde Medical Academy, Mangalore 575018, Karnataka, India. \\ ${ }^{2}$ Department of Pathology, K S Hegde Medical Academy, Mangalore 575018, Karnataka, India.
}

Correspondence to: Dr. Arun Ramdas Menon, Department of Urology, Justice K. S. Hegde Medical College Hospital, Mangalore 575018,

Karnataka, India. E-mail: dr_arunrmenon@yahoo.com

\section{A B S T R A C T}

Renal cell carcinoma (RCC) is well known for its metastatic potential and predilection for unusual sites of metastasis. Metastasis to the bladder is rare and has been reported predominantly from clear cell RCC. We report a case of a 72-year-old male presenting with a bladder tumor which on histopathological evaluation was found to be a metastasis from papillary RCC, 7 years after radical nephrectomy. This case highlights the need to maintain a high index of suspicion to diagnose bladder metastasis in a patient with a history of RCC presenting with a bladder lesion.

Key words: Bladder metastasis; metachronous metastasis; renal cell carcinoma

\section{INTRODUCTION}

Renal cell carcinoma (RCC) metastasizing to the bladder is a rare phenomenon. It can be easily mistaken for primary bladder tumor on cystoscopy. Of the few cases reported in literature, bladder metastasis was predominantly from clear cell RCC. Here, we report a case of bladder metastasis from papillary RCC presenting 7 years after radical nephrectomy.

\section{CASE REPORT}

A 72-year-old male, a chronic smoker, presented with irritative lower urinary tract symptoms. He had undergone left radical nephrectomy for RCC (papillary sub-type, stage T3N0M0) 7 years ago. Clinical examination was unremarkable. His baseline investigations, including complete blood counts and serum biochemistry, were within normal limits. Urine analysis showed microscopic hematuria. A transabdominal sonography revealed a 3 $\mathrm{cm}$ hyperechoic lesion in the left postero-lateral wall of the bladder. Abdominal contrast-enhanced computed tomography (CECT) confirmed the same lesion [Figure 1]. No extra-vesical spread or pelvic lymph node metastasis was evident. The CECT also confirmed that he was post-left radical nephrectomy; there was no evidence of

\begin{tabular}{|l|l|}
\hline \multicolumn{2}{|c|}{ Access this article online } \\
\hline Quick Response Code: & Website: \\
& http://jcmtjournal.com \\
\cline { 2 - 2 } & \\
\hline
\end{tabular}

local tumor recurrence or intra-abdominal metastasis. However, a chest radiograph revealed multiple cannon ball metastases. Cystoscopic examination revealed a solitary, broad-based lesion in the region of the left ureteric orifice [Figure 2]. The rest of the bladder was unremarkable. A cold cup biopsy of the lesion showed a neoplasm arranged predominantly in papillary pattern and focal areas of solid sheets, both composed of tumor cells with moderate eosinophilic cytoplasm and low-grade nuclear features. Immunohistochemistry revealed strong diffuse positivity for cytokeratin 7 (CK7), vimentin and focal positivity for cluster of differentiation 10 (CD10) [Figure 3], suggesting a metastatic bladder tumor from renal papillary adenocarcinoma.

The patient was counseled regarding his disease; he refused active therapy and was referred for palliative care. He died of progressive disease 10 months later.

\section{DISCUSSION}

RCC can be an aggressive disease with the ability to metastasize widely. Besides the common sites of metastasis, i.e. lung, liver, bone and brain, RCC can also metastasize

This is an open access article distributed under the terms of the Creative Commons Attribution-NonCommercial-ShareAlike 3.0 License, which allows others to remix, tweak, and build upon the work non-commercially, as long as the author is credited and the new creations are licensed under the identical terms.

For reprints contact: service@oaepublish.com

How to cite this article: Menon AR, Suresh N, Ravinder P, Puthalath RT. Metachronous bladder metastasis from papillary renal cell carcinoma. J Cancer Metastasis Treat 2016;2:130-2.

Received: 07-07-2015; Accepted: 21-10-2015. 
to unusual sites with myriad presentations. Of the RCC sub-types, clear cell RCC is notorious for its unpredictable metastatic pattern; on the other hand, papillary RCC is

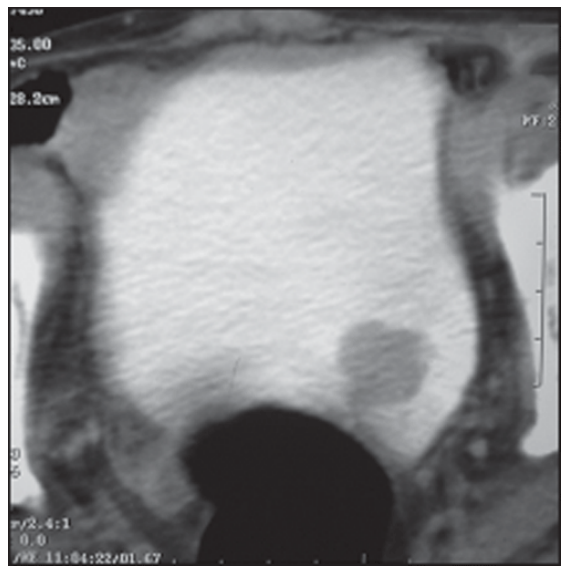

Figure 1: Contrast-enhanced computed tomography: Moderately enhancing lesion in the left postero-inferior wall of the bladder

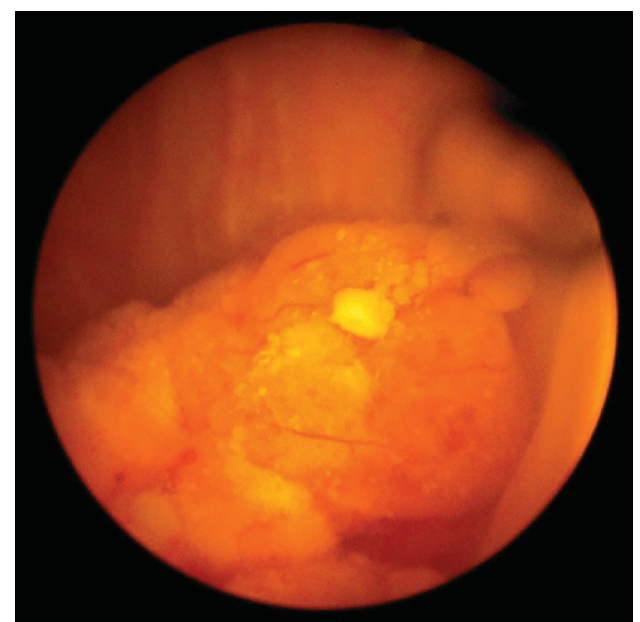

Figure 2: Cystoscopic image: Broad-based non-papillary lesion arising from the region of the left ureteric orifice rarely associated with prodigious metastasis. This has been attributed to its hypovascular nature, owing to the lack of Von Hippel-Lindau mutations that regulate vascular endothelial growth factor, the primary proangiogenic molecule in $\mathrm{RCC}^{[1]}$ The relative rarity of papillary RCC metastatic to the bladder was also demonstrated in a recent series of 11 cases of metastatic RCC to the urinary bladder that were detected over a span of 15 years, with only $18 \%(2 / 11)$ originating from papillary RCC. ${ }^{[2]}$

The bladder is an unusual site for metastasis of RCC with an incidence of $1.6 \%$ in autopsy series. ${ }^{[3]}$ Other metastatic sites of RCC to the genitourinary tract include the ipsilateral ureter, contralateral ureter, ureteric stump and prostatic fossa. Bladder metastasis may be solitary or multiple, the latter having a worse prognosis. Both synchronous and metachronous bladder metastasis from RCC have been described. Metachronous lesions occur more commonly and have been reported to occur up to 12 years after radical nephrectomy. ${ }^{[4]}$ Synchronous lesions are more likely to be associated with the presence of metastasis in other organs.

Although a variety of possible pathways for metastasis of RCC to the bladder have been proposed, the exact mechanism is not clear. $^{[5]}$ Hematogenous spread may occur through the general circulation or retrograde through the periureteric or gonadal veins. In this scenario, the metastasis is usually located within the bladder detrusor layer. Lymphatic spread may occur through the renal hilar lymphatics down the periureteral lymphatics and subsequently through the pelvic lymphatics to the pelvic organs. Transluminal spread with seeding of the distal urothelium may occur, especially in cases where the renal tumor infiltrates the pelvicalyceal system. We believe this to be the likely mechanism in our patient, considering that the site of metastasis was in the region of the left

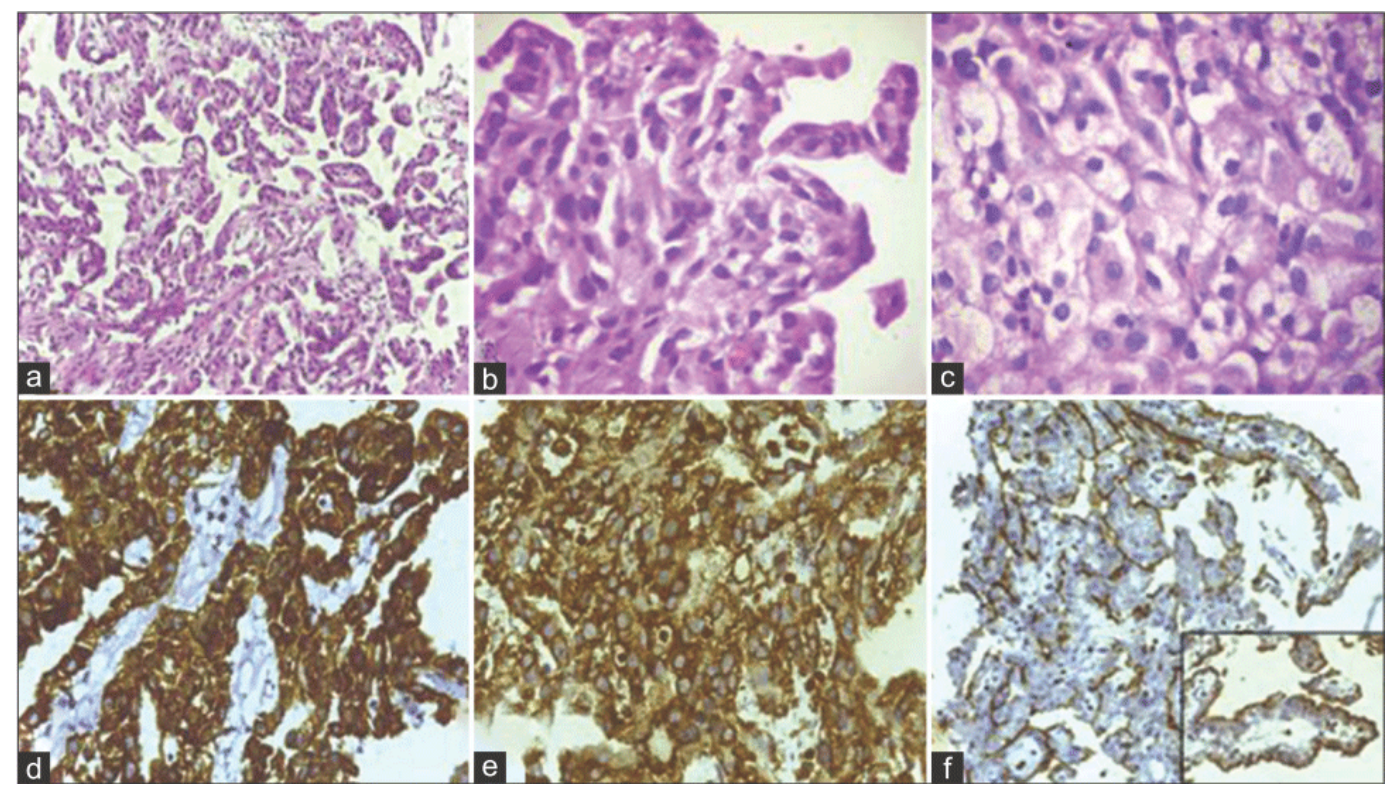

Figure 3: (a-c) Histopathology showing papillary adenocarcinoma with moderate nuclear pleomorphism and eosinophilic cytoplasm. Hematoxylin and Eosin staining section ( $a, \times 4 ; b, \times 40)$; (d) Immunohistochemistry shows strong positivity for cytokeratin 7; (e)vimentin; (f) focal positivity for cluster of differentiation 10 
ureteric orifice and the lesion was primarily situated within the urothelium.

The most common presenting symptom of bladder metastasis is hematuria. In a patient with synchronous bladder metastasis, hematuria may be wrongly attributed to collecting system infiltration of RCC. The bladder metastasis may, thus be overlooked, only to become apparent later, when the patient continues to have hematuria post-nephrectomy. This has led some authors to recommend cystoscopic evaluation in all patients with RCC and hematuria. ${ }^{[4,6]}$

The definitive diagnosis of bladder metastasis is made by cystoscopy and biopsy or transurethral resection. The metastasis histologically resembles their renal primary. However, a basic immunohistochemical panel is useful to differentiate metastasis from poorly differentiated bladder tumors. RCC metastasis, like their primaries, show positive staining for $\mathrm{CK}$ AE1/AE3, CK7, CD10 and vimentin. ${ }^{[4]}$ Well-differentiated primary papillary urothelial carcinomas are positive for CK7 and usually negative for vimentin. Urothelial carcinomas attain vimentin positivity only on sarcomatoid transformation. In diagnostically challenging cases, discriminatory immunohistochemical markers, such as PAX8 and GATA3 positivity, may be used to differentiate metastatic RCC from primary bladder urothelial carcinoma, in addition to alpha-methylacyl coenzyme A racemase positivity for papillary RCC. ${ }^{[2]}$

Due to the rare occurrence of bladder metastasis, there are no established recommendations for management. Metastasectomy has been advocated if complete resection of all metastasis can be accomplished. ${ }^{[7]}$ Management options that have been described, include partial cystectomy or transurethral resection, either as a single modality or in combination with immunotherapy or targeted therapy. ${ }^{[8]}$

Prognosis has been reported to be good only when a single metastasis exists in the bladder. ${ }^{[7,9]}$ To summarise, it must be emphasized that not all papillary tumors of the bladder are primary transitional cell carcinomas. Metastasis from papillary RCC must also be considered in a patient with a history of renal malignancy presenting with hematuria or a bladder mass. As in our case, these metastases may present several years after treatment of the primary malignancy.

\section{Financial support and sponsorship} Nil.

\section{Conflicts of interest}

There are no conflicts of interest.

\section{REFERENCES}

1. Campbell SC, Lane BR. Malignant renal tumors. In: Wein AJ, editor Campbell-Walsh Urology. 10th ed. Philadelphia: Saunders; 2011. p. 1433-4.

2. Zhang M, Wah C, Epstein JI. Metastatic renal cell carcinoma to the urinary bladder: a report of 11 cases. Am J Surg Pathol 2014;38:1516-21.

3. Gelister JS, Falzon M, Crawford R, Chapple CR, Hendry WF. Urinary tract metastasis from renal carcinoma. Br J Urol 1992;69:250-2.

4. Masayo K, Kyoko I, Kyoko H, Tohru T. Bladder metastasis of renal cell carcinoma: a case study. Acta Urol Jpn 2007;53:571-4.

5. Doo SW, Kim WB, Kim BK, Yang WJ, Yoon JH, Jin SY, Yun SS. Metastasis of renal cell carcinoma to the bladder. Korean J Urol 2013;54:69-72.

6. Swanson DA, Liles A. Bladder metastasis: a rare cause of hematuria in renal cell carcinoma. J Surg Oncol 1982;20:80-2.

7. Russo P, O’Brien MF. Surgical intervention in patients with metastatic renal cancer: metastasectomy and cytoreductive nephrectomy. Urol Clin North Am 2002;35:679-86.

8. Matsuo M, Koga S, Nishikido M, Noguchi M, Sakaguchi M, Nomata K, Maruta N, Hayashi T, Kanetake H. Renal cell carcinoma with solitary metachronous metastasis to the urinary bladder. Urology 2002;60:911-2.

9. Raviv S, Eggener SE, Williams DH, Garnett JE, Pins MR, Smith ND. Long-term survival after "drop metastases" of renal cell carcinoma to the bladder. Urology 2002;60:697. 